\title{
Benign rheumatoid nodules in a woman with chronic lymphocytic leukaemia and borderline lepromatous leprosy
}

\author{
Philip R Cohen, Razelle Kurzrock
}

\begin{abstract}
Objectives-To report benign rheumatoid nodules in a woman with chronic lymphocytic leukaemia and borderline lepromatous leprosy and to summarise the features of the patients with adult onset benign rheumatoid nodules.

Methods-A 66 year old woman with chronic lymphocytic leukaemia and borderline lepromatous leprosy who presented with subcutaneous elbow nodules, which were at first suspected to represent either progression of her haematological disease or leprosy, is described. The clinical characteristics of our patient and previous reports of another 24 subjects with adult onset benign rheumatoid nodules are reviewed. Results-Biopsy of the patient's subcutaneous lesion disclosed the histopathology of a rheumatoid nodule; serological and clinical evaluations for rheumatoid arthritis and other rheumatoid nodule associated systemic diseases were negative. Adult onset benign rheumatoid nodules are clinically and histologically identical to those found in patients with rheumatoid arthritis. They often appeared in women during their $20 \mathrm{~s}$, frequently resolved spontaneously or were adequately treated by excision, and recurred in about one third of patients. The lesions were located in the ocular adnexa in $60 \%$ of patients. The most common lesional sites in patients with non-ocular benign rheumatoid nodules were the elbows, feet, and knees. None of these patients subsequently developed rheumatoid arthritis or other rheumatoid nodule associated diseases during follow up periods of as long as 20 years.
\end{abstract}

Conclusion-The appearance of subcutaneous nodules is often the harbinger of an associated systemic disorder. Although benign rheumatoid hodules occur infrequently in adults, they should be considered in the differential diagnosis of new nodular lesions.

(Ann Rheum Dis 1993; 52: 685-688)

Benign rheumatoid nodules usually appear in childhood and are morphologically and histologically indistinguishable from the subcutaneous nodules found in patients with rheumatoid arthritis. We describe the case of a 66 year old white woman with chronic lymphocytic leukaemia and borderline lepromatous leprosy who developed benign rheumatoid nodules. Her subcutaneous nodules initially appeared at the age of 61 years and have remained asymptomatic. To the best of our knowledge this subject is the oldest reported patient with benign rheumatoid nodules and the only reported case of this disorder in a person with leukaemia and leprosy.

A review of the literature shows that adult onset benign rheumatoid nodules have previously only been reported in 24 subjects. ${ }^{1-10}$ Underlying disorders in several of these patients have included hypertension, local trauma, and pregnancy, though most subjects had no associated disorder. As in our patient, no clinical nor serological evidence of rheumatoid disease developed, even after long term follow up.

\section{Case report}

A 56 year old woman was diagnosed with chronic lymphocytic leukaemia in January 1982. She was treated intermittently with chlorambucil and prednisone over the next three years. Beginning in November 1986, monthly treatment with fludarabine was initiated for progressive disease. She achieved a partial remission in April 1987 after receiving five courses of this treatment.

In February 1987 a chronic rash on her right arm was noted to have become erythematous. By April 1987 additional infiltrative lesions were present on her arms, legs, abdomen, and back. A lesional biopsy sample established the diagnosis of borderline lepromatous leprosy; additional information was obtained that armadillos were present around the patient's house in Sealy, Texas. Treatment with clofazimine and dapsone by mouth was started. She stopped developing new lesions and her ulcerated plaques and nodules progressively healed. In September 1991 her lepromatous disease was found to be inactive, yet she continues her life long treatment with dapsone.

When the cutaneous lesions of leprosy began to develop, the patient also noted the appearance of tender subcutaneous nodules overlying her elbows. The nodules were thought to represent neural disease secondary to leprosy. Initially the nodules became less
Medical School,

6431 Fannin, Suite 1.186, Houston, TX 77030, USA

Accepted for publication 22 April 1993 


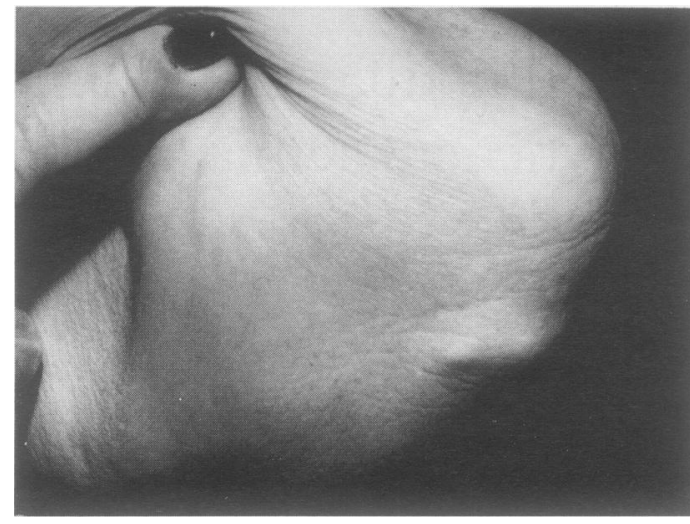

Figure 1 Subcutaneous adult onset benign rheumatoid nodule on the left elbow.

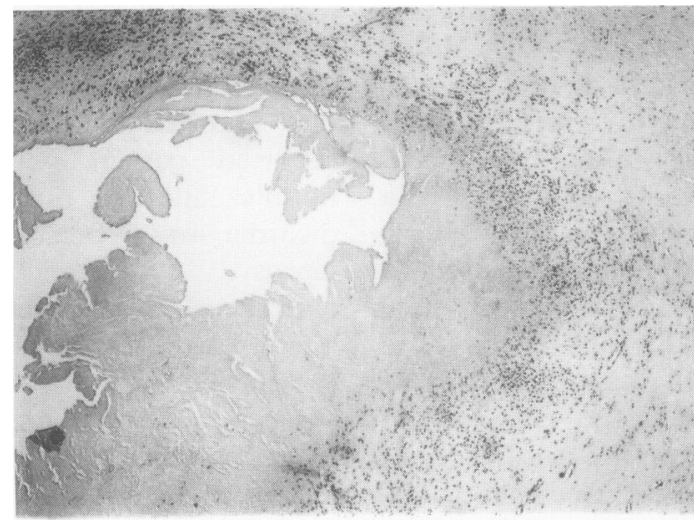

Figure 2 Microscopic examination of the benign rheumatoid nodule shows a central area of fibrinoid necrosis surrounded by a palisading granuloma of monocytes and lymphocytes (haematoxylin and eosin).

painful and softened after antimycobacterial treatment was started. However, despite an improvement in her leprosy related skin lesions, her elbow nodules persisted. When the patient was seen in November 1990 her chronic lymphocytic leukaemia had progressed. Treatment with subcutaneous $\alpha$ interferon and prednisone by mouth for five days each month was begun, with partial control of her disease.

Clinical examination in August 1991 showed asymptomatic, bilateral, $1.0 \times 1.5 \mathrm{~cm}$ subcutaneous nodules at the olecranon (fig 1). They were not fixed to the underlying bone; the overlying skin did not adhere to the nodules and could easily be moved. The histological features of a lesional biopsy sample were characteristic of a rheumatoid nodule. There was a palisading granuloma surrounding a central area of fibrinoid necrosis located in the deep dermis and subcutaneous fat. The inflammatory infiltrate was predominantly composed of monocytes adjacent to the central necrosis and lymphocytes located more peripherally; there was no evidence of malignancy (fig 2). Special stains were negative for fungi and myocbacteria.

No joint pain or morning stiffness was present; repeat examination did not show any bony abnormalities of the hands or other sites. Serological evaluation for rheumatoid factor was negative. Thus clinicopathological correla- tion of the lesions that had been present for five years was consistent with the diagnosis of benign rheumatoid nodules.

\section{Discussion}

Benign rheumatoid nodules are subcutaneous nodules, histologically indistinguishable from those occurring in patients with rheumatoid arthritis, that typically occur in otherwise healthy children who have neither clinical nor serological manifestations of an associated rheumatological or other disease. These nodules have also been designated as nonrheumatoid rheumatoid, palisading granuloma nodosum, pseudorheumatoid, pump bumps, rheumatic-like, rheumatoid-like, and subcutaneous palisading granuloma. ${ }^{59}$ Microscopic examination shows a homogeneous central area of fibrinoid necrosis surrounded by palisading fibroblasts, macrophages, and monocytes; vascular connective tissue with lymphocytes and plasma cells comprise the peripheral zone of the nodule. In addition to benign rheumatoid nodules, subcutaneous nodules with similar histopathological features may be observed in patients with agammaglobulinaemia with polyarthritis, subcutaneous granuloma annulare, Jaccoud's syndrome, necrobiosis lipoidica, rheumatic fever, rheumatoid arthritis, rheumatoid nodulosis, and systemic lupus erythematosus. ${ }^{311}$

The initial appearance of benign rheumatoid nodules in a person aged 18 years or older is rare. Including our patient, only 25 subjects with adult onset benign rheumatoid nodules have been described. ${ }^{1-10}$ Previously reported patients with 'adult onset benign rheumatoid nodules' who subsequently developed rheumatoid arthritis ${ }^{12}$ or had a positive rheumatoid factor, or both, ${ }^{211-13}$ were excluded from this review. Reports without histological confirmation of the subcutaneous nodules were also not included. ${ }^{14} 15$ Of the subjects, including this patient, with adult onset benign rheumatoid nodules, 14 were women, ${ }^{1-367910}$ and eight were men $^{2-5}$; the sex was not reported for three patients. $^{8}$

When the subcutaneous nodules were initially noted the patients ranged in age from 18 years $^{2}$ to 61 years (this paper) (median age 23 years). The nodules were often found around the eyes (15 patients) ${ }^{2}{ }^{10} ; 11$ subjects had non-ocular benign rheumatoid nodules which were located on the elbows (three patients, including this patient), ${ }^{5-7}$ feet (three patients), ${ }^{134}$ knee (two patients), ${ }^{35}$ and the ankle, ${ }^{3}$ chin, ${ }^{2}$ hands, ${ }^{4}$ or shoulders ${ }^{3}$ (one patient each) (table). One of the patients had ocular and non-ocular benign rheumatoid nodules: a 26 year old white woman with a previous history of recurrent nodules at the lateral and medial canthus of both eyes for five years subsequently developed a similar lesion on her chin. ${ }^{2}$

The benign rheumatoid nodules recurred in eight $(36 \%)$ of 22 subjects. $^{1-4}{ }^{10}$ Follow up of the 25 patients with adult onset benign rheumatoid nodules ranged from less than one year to as long as 20 years ${ }^{4}$; the median follow 
Clinical characteristics of eight patients with non-ocular adult onset benign rheumatoid nodules. Another three patients (not shown) have been described with subcutaneous nodules in the palm (one patient) or scattered over the feet (two patients). All were adults less than 26 years old and remained well during follow up of 4.5 years $^{8}$

\begin{tabular}{|c|c|c|c|c|c|c|c|c|}
\hline \multirow[t]{2}{*}{ Sex } & \multirow[t]{2}{*}{ Race } & \multirow{2}{*}{$\begin{array}{l}\text { Age } \\
\text { (years) }\end{array}$} & \multicolumn{3}{|c|}{ Subcutaneous nodules } & \multirow{2}{*}{$\begin{array}{l}\text { Follow up } \\
\text { (years) } 9\end{array}$} & \multirow[t]{2}{*}{ Comments } & \multirow[t]{2}{*}{ Reference } \\
\hline & & & Location $†$ & Treatment & Recurrence\$ & & & \\
\hline Female & NS & 20 & $\begin{array}{l}\text { Plantar } \\
\text { feet }\end{array}$ & $\begin{array}{l}\text { Excision }(-) \text {, gold }(-) \text {, rest }(-), \\
\text { shoe cushion }(-), \text { steroid } \\
\text { treatment }(-), \text { spontaneous } \\
\text { resolution after } 3.5 \text { years }(+)\end{array}$ & Yes & $4 \cdot 75$ & $\begin{array}{l}\text { Nodules resolved after } \\
\text { childbirth and recurred } \\
\text { seven months later }\end{array}$ & 1 \\
\hline Female & White & 21 & $\begin{array}{l}\text { Canthus } \\
\text { chin }\end{array}$ & $\begin{array}{l}\text { Excision }(-) \text {, spontaneous } \\
\text { resolution after } 0.3 \text { years }(+)\end{array}$ & Yes & 14 & $\begin{array}{l}\text { Initially presented with ocular } \\
\text { nodules }\end{array}$ & 2 , case 3 \\
\hline Female & White & 26 & $\begin{array}{l}\text { Ankle, } \\
\text { foot, } \\
\text { knee }\end{array}$ & Excision $(-)$ & Yes & 18 & $\begin{array}{l}\text { Nodules recurred with } \\
\text { pregnancy }\end{array}$ & 3 , case 9 \\
\hline Male & NS & 26 & $\begin{array}{l}\text { Shoulders } \\
\text { (deltoid } \\
\text { area) }\end{array}$ & $\begin{array}{l}\text { Excision }(+) \text {, spontaneous } \\
\text { resolution after } 0.5 \text { years }(+)\end{array}$ & No & $0 \cdot 5$ & $\begin{array}{l}\text { Nodules preceded by injections } \\
\text { and trauma to the area }\end{array}$ & 3 , case 10 \\
\hline Male & White & 32 & $\begin{array}{l}\text { Fingers, } \\
\text { palm, } \\
\text { toe }\end{array}$ & Excision (-) & Yes & 20 & Hypertensive & 4 \\
\hline Male & White & 47 & $\begin{array}{c}\text { Elbow, } \\
\text { knee }\end{array}$ & $\begin{array}{l}\text { Excision }(+) \text {, spontaneous } \\
\text { resolution after } 13 \text { years }(+)\end{array}$ & No & 13 & Hypertensive & 5 \\
\hline Female & NS & 56 & Elbows & $\begin{array}{l}\text { Biopsy }(-) \text {, spontaneous } \\
\text { resolution after seven years }(+)\end{array}$ & No & 12 & $\begin{array}{l}\text { Nodules resolved after } \\
\text { splenectomy }\end{array}$ & 6,7 \\
\hline Female & White & 61 & Elbows & Biopsy $(-)$ & No & 5 & $\begin{array}{l}\text { Borderline lepromatous leprosy } \\
\text { and chronic lymphocytic } \\
\text { leukaemia }\end{array}$ & This paper \\
\hline
\end{tabular}

Abbreviations: NS=not stated.

*Age when nodules initially appeared.

tLocation of original or recurrent lesions, or both.

$\neq(+)$ Successful or $(-)$ unsuccessful treatment (either no resolution or recurrence of lesion).

$\ddagger(+)$ Successful or $(-)$ unsuccessful treatment (either no resolution or recurrence of lesion).
SRecurrence of a nodule at site of previous lesion after successful treatment or spontaneous resolution of previous lesion.

$\$$ Recurrence of a nodule at site of previous lesion after successful treatment or spontaneous resolution of previous lesion. disease associated with rheumatoid nodules has occurred.

up time for all patients was five years. None of these subjects developed serological or clinical symptoms of rheumatoid arthritis or another disease associated with rheumatoid nodules during that period.

Adult onset benign rheumatoid nodules of the ocular adnexa typically occurred in young women (10 of 15 patients), often resolved either after excision or without treatment, and only recurred in approximately one third of subjects. ${ }^{2910}$ Specifically, the patient's age at the onset of their nodules ranged from 18 to 30 years (median 21 years). Thirteen of the patients were reported by Rao and Font ${ }^{2}$; they observed that 'the lesions had a tendency to regress spontaneously'. ${ }^{2}$ Neither treatment nor follow up was described for a 29 year old woman with multiple episcleral, eyebrow, eyelid, and orbital benign rheumatoid nodules. ${ }^{9}$ The remaining patient with ocular benign rheumatoid nodules was a 23 year old woman with multiple recurrent lesions. ${ }^{10}$ Although new nodules would appear after excision, intralesional injection of corticosteroids resulted in regression of the lesions. ${ }^{10}$

Compared with the adults with ocular benign rheumatoid nodules, non-ocular adult onset benign rheumatoid nodules were usually observed in slightly older women (five of eight patients) who ranged in age from 20 to 61 years (median 26 years) (table). The lesions recurred in half $(4 / 8)$ of these subjects. Similar to the patients with ocular benign rheumatoid nodules, the lesions spontaneously resolved in several of the subjects with non-ocular benign rheumatoid nodules: in five $(63 \%)$ of eight subjects the nodules regressed without treatment within four months to 13 years (median seven years). Although the nodules were adequately excised without subsequent recurrence in two patients, the lesions again appeared after excision in four patients. A 20 year old woman with multiple recurrent plantar nodules did not respond to several attempted therapeutic interventions: excisional biopsy, intralesional methylprednisolone acetate injections, auranofin by mouth, rest, or shoe cushioning. ${ }^{1}$ Interestingly, all of her lesions began to soften within three days of the delivery of her first child and had completely disappeared within two weeks of the delivery; seven months later, two small plantar nodules reappeared. ${ }^{1}$ In contrast, a 26 year old white woman with multiple benign rheumatoid nodules noted that the onset of recurrent lesions was temporally associated with pregnancy. $^{3}$

In addition to pregnancy, ${ }^{13}$ several of the subjects with non-ocular adult onset benign rheumatoid nodules had previous or concurrent, local or systemic disorders. Injections and trauma to the deltoid areas of a 26 year old man preceded the appearance of benign rheumatoid nodules located on the corresponding shoulders. ${ }^{3}$ Hypertension, requiring systemic treatment, was present in two patients. ${ }^{4}$ Two patients had also had a splenectomy to treat a traumatic rupture from an automobile accident ${ }^{4}$ or thrombocytopenic purpura $^{6}$; the elbow nodules of the latter patient (which had been present for seven years) resolved spontaneously during the same year that the operation was performed. ${ }^{67}$ The number of patients with non-ocular adult onset benign rheumatoid nodules is too small to establish definitively whether any of these disorders are indeed causally related to the development, persistence, or resolution of benign rheumatoid nodules in these subjects.

1 Sibley J T. Pregnancy and benign rheumatoid nodules [letter]. Am f Med 1986; 81: 1124 .

2 Rao N A, Font R L. Pseudorheumatoid nodules of the ocular adnexa. Am $\mathcal{F}$ Ophthalmol 1975; 79: 471-8. 3 Williams H J, Biddulph E C, Coleman S S, Ward J R 
Isolated subcutaneous nodules (pseudorheumatoid). $\mathcal{F}$ Bone foint Surg [Am] 1977; 59: 73-6.

4 Akers W A, Miller D A. Rheumatoid nodules in adults withou rheumatoid arthritis. Arch Dermatol 1966; 93: 428-31.

5 Causey J Q. Isolated subcutaneous rheumatic-like nodules in an adult. South Med f 1972; 65: 633-4.

6 Roxburgh A C. Three cases of granuloma annulare. $\mathrm{Br} f$ Dermatol 1936; 48: 633-4.

7 Bowers R E. The histology of granuloma annulare compared with that of the necrobiotic nodules of compared with that of the necrobiotic nodules

8 Elliott G B, Hill R H, Kliman M R, Elliott J D A. Deep granuloma annulare and 'non-rheumatoid rheumatoid nodule'

9 Ross M J, Cohen K L, Peiffer R L Jr, Grimson B S Episcleral and orbital pseudorheumatoid nodules. Arch Ophthalmol 1983; 101: 418-21.
10 Pye R J, Greaves $M$ W. Benign rheumatoid nodules of the skin. Br f Dermatol 1979; 101 (suppl 17): 58-9.

11 Belin D C, Abeles M, Weinstein A. Rheumatoid markers in the absence of arthritis. I Rheumatol 1979; 6: 293-9.

12 Lowney E D, Simons H M. 'Rheumatoid' nodules of the skin: their significance as an isolated finding. Arch Dermatol 1963; 88: 853-8.

13 Askari A, Moskowitz R W, Goldberg V M. Subcutaneous rheumatoid nodules and serum rheumatoid factor without arthritis. $\mathcal{F} A M A$ 1974; 229: 319-20.

14 Fowler J K. Subcutaneous nodules occurring in an adult not the subject of rheumatism. BMF 1884; i: 107.

15 Short C L, Bauer W, Reynolds W E. Nodules. In: Rheumatoid arthritis: a definition of the disease and a clinical description based on a numerical study of 293 patients and controls. Cambridge: Harvard University Press, 1957: $326-30$

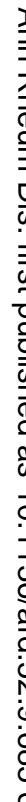

(\$) 